\title{
COMMENTARY
}

\section{Advocacy Groups Are Crucial Players in Developing New Neurotherapeutics}

\author{
Beryl Lieff Benderly
}

\section{INTRODUCTION}

Advocacy groups can play a crucial role in speeding new neurotherapeutics to market because the drug development process offers several important opportunities for them to exert influence. This encouraging message emerged from talks by three national experts at the Advocacy Forum that kicked off the 6th Annual Meeting of the American Society for Experimental NeuroTherapeutics (ASENT) in Bethesda, Maryland on March 11, 2004. An audience of nearly 60 advocacy group representatives learned about these opportunities and strategies for taking advantage of them at the forum entitled "Neurotherapeutics Development-A Roadmap for Advocacy Groups.” By understanding the missions, needs, and constraints that influence university-based researchers, federal regulators, and pharmaceutical companies, the speakers explained, advocacy groups can tailor workable and effective interventions that can pay off in getting more treatments to patients sooner. By bringing to bear their expertise in how the disorder most significantly affects patients, furthermore, advocacy groups can help focus research on the issues of greatest concern.

Carefully targeted funding, even in relatively small amounts, has the power to attract talented academic scientists into research on particular disorders and then hold them throughout their careers, explained David A. Roth, M.D., formerly a full-time faculty member at Harvard Medical School and now a director of clinical research and development at Wyeth Research. His presentation described the workings of university research. The organization and expertise of advocacy groups can hasten clinical trials and draw attention to particular disorders as well as their most significant aspects, said Marc Walton, M.D., Ph.D., of the Biological Therapeutics Internal Medicine Products Division of the Food and Drug Administration (FDA), who explained the role of federal

B.L.B. is a science writer in Washington, DC.

Correspondence should be addressed to Beryl Lieff Benderly, Inc., 3630 Patterson Street NW, Washington, DC 20015. E-mail: blbink@aol.com. regulators. Action at key points in drug development programs of pharmaceutical companies can influence which drugs receive the investment needed to come to market, noted Christopher Gallen, M.D., Ph.D., Vice President of Clinical Operations at Wyeth, who outlined the decision-making process of large pharmaceutical companies.

\section{WORKING WITH ACADEMIC SCIENTISTS}

University scientists struggling to climb the academic career ladder do most of the basic science that results in new treatments, Roth stated. By helping them achieve the "personal career advancement" that they seek, advocacy groups can recruit research talent to a disorder of interest, Roth said. By providing the specific aid that researchers need at particular points in their careers, advocacy groups can build and maintain their commitment to working on the disease.

At the start of a research career, for example, a postdoctoral trainee must make the difficult but critical transition from working on a mentor's projects to winning independent grants in his or her own right from the National Institutes of Health or other major funding sources. Small research scholarships for initial independent work can lift young scientists above the competition and equip them to win the pivotal first grant that establishes a career, Roth said. Financing such young-scientist awards can begin a long-term relationship between talented researchers and a particular disorder.

Next, as researchers' careers develop, advocacy groups can create other mechanisms that raise their professional standing through work on the disorder, Roth continued. Successful scientists must study important problems and produce significant results, producing prominent publications and participating in prestigious meetings, boards, and other gatherings of colleagues. Advocacy organizations that help researchers meet each of these needs can make them into become long-standing "friends" of both their disorder and the organization, Roth continued. 
Competitive research grants funded by advocacy groups, for example, can assist productive scientists in generating the "publications of high quality and quantity" that they need, Roth said. Advocates' expert knowledge of the impact of the disease on patients can help guide the researchers toward fertile and useful areas of research. Organizations are superbly equipped to motivate patients to participate in clinical trials and cut the time needed to complete studies. They can sponsor meetings and journals that provide scientists and their work exposure and publication opportunities. They can develop scientific advisory boards that gain researchers national or even international prominence while using their expertise to identify the most promising areas for future support.

Legislative action to obtain additional government funding, public education campaigns to encourage private fundraising and build popular support, and collaborations with professional organizations in related fields are other initiatives that organizations can undertake to aid research and researchers, Roth said. Through a clear vision, effective organization, strong leadership, solid support, and a focus on patient needs, advocacy groups can build relationships with academic scientists that benefit both parties, producing professional advancement on the one hand and advances in knowledge and therapeutics on the other.

\section{ROLE OF FDA AND INTERACTIONS WITH FDA IN THERAPEUTIC PRODUCT DEVELOPMENT}

The second speaker of the forum, Marc Walton, Director, Division of Biological Therapeutic Internal Medicine Products, Center for Drug Evaluation and Research (CDER) at the FDA, explained the role of federal regulation in drug development and methods that advocacy groups can use to help speed the process. The Food and Drug Administration, legally mandated to ensure the safety and effectiveness of therapies, oversees the clinical studies required to bring drugs to market. The three major roles of the agency in that process are protecting study volunteers' rights and safety, advising study sponsors on the quality of their studies, and granting approval to market medical products. Study quality, he said, means "keeping in mind the goals of clinical studies," which are to evaluate and create new therapeutics and design trials that produce useful new information.

The authority, responsibilities, procedures, and standards of the agency are strictly defined by laws, regulations, and advisory guidances, he said. Its interactions with product manufacturers and clinical investigators concerning specific products designed or intended for specific uses are confidential. But within those parameters, FDA personnel have a "broad perspective" on meth- ods to achieve "effective and efficient" studies that avoid the two major types of errors, he said. They are the type I error of wrongly concluding that a product works when it doesn't, and the type II error of "missing something we want to know about."

Advocacy groups can help study sponsors and investigators design high-quality, informative studies by encouraging them to view the drug development process as a whole and not as a series of separate studies, Walton advised. They should encourage drug developers not to undertake expensive late-stage trials before a sufficient number of careful, smaller trials have been done to ensure that, when the large trial starts, "the right study is done."

Advocacy groups can significantly cut the time needed for trials by organizing patients to participate because recruitment is an "important element in the time" it takes to move a drug to approval, Walton continued. Though the FDA cannot take part in such an organizational effort, the agency is "very happy" to assist groups in educating potential subjects about the drug approval process, he said.

Bringing research opportunities to the attention of drug manufacturers is "not part of the formal role of the FDA," he continued. The agency's Orphan Drug Office, however, works to promote "innovative thinking" on rare diseases and can fund early studies. In addition, individuals and small groups of FDA staffers in other sections also help in bringing promising ideas to the attention of companies. Clinical review sections can apprise companies of connections they see that "may help them on to new efforts," he added. Advocacy groups can support these efforts by keeping strategically placed agency officials apprised of new developments and important issues.

\section{BECOMING FRIENDS WITH PHARMA}

In the final analysis, however, it is the pharmaceutical industry that moves drugs from initial concept to clinical use. The industry sees itself "as wearing the white hat" in a continuing — and increasingly difficult—struggle against human suffering, said Gallen, the final speaker. But the research and development that advances human welfare can only be supported out of the sales of each company. Spending $\$ 0.17$ of every dollar earned on drug development, these corporations make "the heaviest investment on R\&D" of any industry, he said.

At present, "a lot of companies are betting heavily" on CNS drugs and "a lot of compounds are being tested," Gallen continued. Because the "brain is a very complicated organ," however, there are "a lot of ways for drugs that go into the brain to fail," and the great majority of candidate compounds do. For every 10,000 compounds screened for possible use as a pharmaceutical, one makes 
it to market; only $15 \%$ of the CNS drugs in very expensive late-stage testing succeed in winning approval. In recent years only about $2 \%$ of compounds tested in humans eventually succeed to win approval as therapeutics. The rates of failure are staggering. Because no one knows beforehand which compounds will succeed, the few compounds that do so must eventually earn the money to pay for the costs of all the research conducted on the many drugs that fail. Every effort to develop a new neurotherapeutic is therefore a "huge investment."

Beyond that, such investments carry a high risk. Patents restrict the time that a company will make money on a drug, so the sooner it gets to market, the better its chances of recouping the investment. CNS drugs, however, now take longer than any other category and in recent years discovery and development times have been increasing and success rates falling. Still, companies continue to pursue new CNS drugs because the "unmet medical need" is huge, Gallen said.

The decision to start development of a drug combines scientific and financial factors, he explained. The calculation weighs both the chances that the drug will work and its potential for market success. "Significant opportunities" for pharmaceutical companies and advocacy groups "to help one another" exist in every phase of development, Gallen said.

Drug development begins with the discovery team, which identifies potentially promising possibilities. Ideas often come from basic research by university or government scientists. The development strategy team examines the possibilities from a therapeutic perspective. The product team devises a marketing plan, determining medical indications and answering such questions as whom the disorder affects and how seriously, what competing treatments exist and what they cost.

Advocacy groups can influence the discovery stage through targeted support of academic scientists and small studies that produce ideas suggesting new therapeutic approaches. Such support can become "a tremendously leveraged investment," Gallen said. Advocacy groups should see that their researchers are "vocal," presenting their work widely and bringing it to the attention of company discovery scientists. Advocates can also track the thinking of companies at this early stage by following patent applications because any promising leads will be patented, Gallen said. Contacting companies at this point can be influential, he added.

Working with the development strategy team, advocacy groups' scientific advisors can help industry clinicians clarify therapeutic issues by letting them know which aspects of the disorder have the greatest impact on patients. "Patients care about the disability, not the neurology, Patients are focused on the fact that they can't walk more than on the neurology that they have increased motor tone or increased reflexes." Thus, they can tell companies "what's important, which symptoms and features really matter to patients," Gallen said. Advocates also assist the product team in shaping the marketing strategy with expert information on the patient population, its needs, desires, and preferences. Then, when the drug moves into trials, advocacy groups have a key role to play in informing, mobilizing and recruiting subjects. For maximum success, advocates should build relationships with companies early in the drug development process, at least 2 to 3 years before projected launch, he advised.

Over a period of only a few years, advocacy groups have become a "powerful and well represented" part of ASENT, said Rosalie Lewis, an ASENT board member who organized the forum. Armed with the strategies outlined by the speakers, advocates can more effectively work to bring new neurotherapeutics to the clinic. The patients, she said, "need to know there is hope." 